EDUCATION

MJPCH Vol. 26 (1) June 2020
OFFICIAL JOURNAL

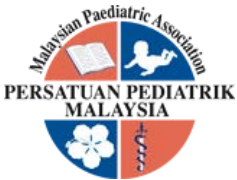

\title{
A CHILD WHO REFUSED FEEDING AFTER PLAYTIME
}

\author{
Irfan Mohamad', Mohamad Muizz Mohamad'2, Wan Emelda Wan Mohamad'2, Suhaimi \\ Yusuf $^{2}$
}

Received: 5 April 2020; Accepted revised manuscript: 11 May 2020

Published online: 14 June 2020

\section{Case Summary}

A 10-month-old boy was brought to the Emergency Department when his mother noticed sudden episodes of choking while playing with his 4-year-old sister at home. It was associated with bluish discoloration of the face for a few minutes and 2 episodes of vomiting. There were blood streaks in the vomitus. Since then, the child refused breastfeeding. The mother immediately brought the child to the hospital.
Physical examination revealed that the patient was irritable and had normal vital signs, except for the presence of tachycardia. He was not in respiratory distress. Intra-oral examination was unremarkable. Lateral neck and chest radiographs were obtained (Figure 1).

What is your diagnosis?

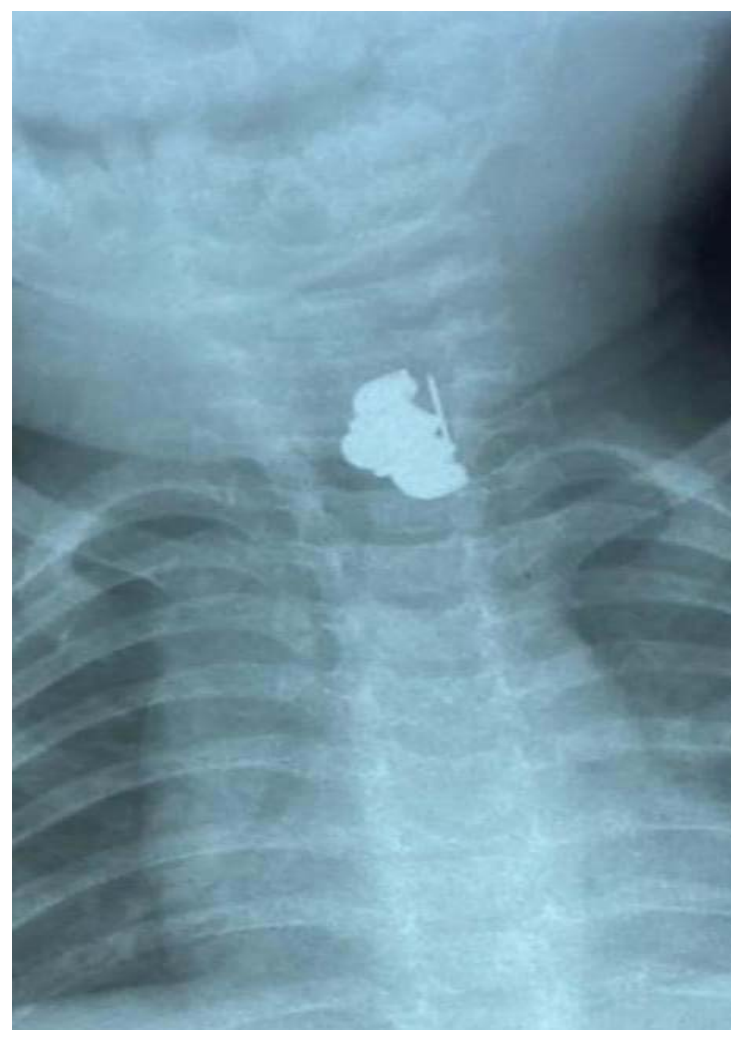

Figure 1: Chest radiograph of the child

\footnotetext{
'Department of Otorhinolaryngology-Head \& Neck Surgery, School of Medical Sciences, Universiti Sains Malaysia, Kelantan, Malaysia
} ${ }^{2}$ Department of Otorhinolaryngology-Head \& Neck Surgery, Hospital Tengku Ampuan Afzan, Kuantan, Pahang, Malaysia

Corresponding author: Assoc. Prof. Dr. Irfan Mohamad, Department of Otorhinolaryngology-Head \& Neck Surgery, School of Medical Sciences, Universiti Sains Malaysia Health Campus, 16150 Kota Bharu, Kelantan, Malaysia

Tel: 609-7676420; Email: irfankb@usm.my 


\section{Answer:}

The chest radiograph revealed an opaque foreign body in the pharynx or upper oesophagus. The foreign body had a sharp-pointed end and was most likely a pin.

The patient was taken to the operation theatre for examination under anaesthesia and removal of the foreign body. Intraoperatively, the foreign body was found to be at the level of the cricopharyngeus, $15 \mathrm{~cm}$ from the upper oesophageal sphincter. It was a brooch that belonged to the mother (Figure 2). The pin was embedded in the oesophageal wall, and some manoeuvres were needed to remove it without causing additional trauma. As the pin was embedded and pointing upwards, the brooch was pushed down before it was removed using an oesophagoscope. Post removal, minimal abrasion was noted. A nasogastric tube was inserted for feeding for 2 days, and dexamethasone was initiated to reduce oedema. The patient was discharged well on the third day without any residual symptoms.

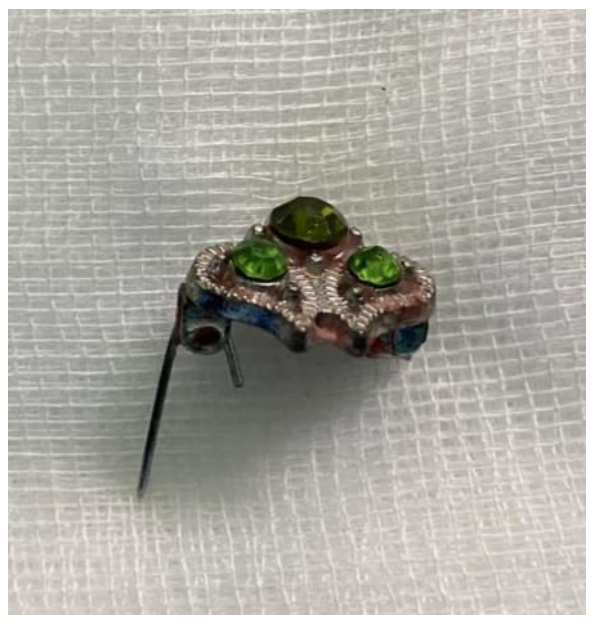

Figure 2: Brooch taken out from oesophagus

\section{Discussion}

The presence of foreign bodies is very common in children, especially in toddlers. A coin is the most common foreign body found in children. Due to its round shape, it is less dangerous compared to the foreign body in our case. A brooch with an open sharp-pointed pin can easily traumatise the pharynx and oesophagus. Thus, in our case, the open pin led to the symptom of pain during feeding, while the brooch itself obstructed swallowing. The presence of blood streaks in the vomitus could be due to direct mucosal trauma. Similar symptoms usually manifest if a hairpin is ingested or aspirated.

Dysphagia is the most common symptom of the presence of an airway foreign body, besides the observation of ingestion by the family [1]. In our case, the patient was too young to speak and the history did not lead to a definitive diagnosis. Thus, a history of obstructive symptoms, such as dysphagia, refusing feeding and vomiting after attempts of swallowing, can be suggestive of the presence of a foreign body in the upper aerodigestive tract. The mother made a wise decision to immediately bring the child to the hospital. The initial brief episode of cyanosis may be attributed to the size of the brooch, which obstructed the oropharynx before it went downwards and posteriorly propelled to enter the digestive tract. Fortunately, the brooch did not dislodge into the larynx.

A brooch or hairpin is a relatively common foreign body among patients from the Middle East or Muslim-predominant countries, especially adolescent Muslim girls [2]. However, the typical location of the foreign body is the airway rather than the digestive tract. This is because girls usually hold pins (which they use to set their headscarves) between their lips, and whenever there is a loss of focus, the pins can easily be inhaled and reach the airways [3].

\section{References}

[1] Dereci S, Koca T, Serdaroğlu F, Akçam M. Foreign body ingestion in children. Turk Pediatri Ars. 2015;50(4):234-240. doi:10.5152/TurkPediatriArs.2015.3164

[2] Hamad AM, Elmistekawy EM, Ragab SM. Headscarf pin, a sharp foreign body aspiration with particular clinical characteristics. Eur Arch Otorhinolaryngol. 2010 Dec;267(12):1957-62. doi: 10.1007/s00405-010-1295-y.

[3] Noh KB, Salim R, Abdullah MS, Mohamad I. Metallic hair pin aspiration into the left tertiary bronchus. Malays Fam Physician 2018;3(2):36-8. 